\section{THE PINEAPPLE AS A DIGESTIVE AID.} To the Editors of THE LANCET.

SIRs, - The value of the pineapple as a proteid digestive I can fully confirm, not only from personal experience at the table but also from experiments in vitro. Its active principle, bromoline, has long been used in the preparation of Masquera's beef jelly, a most satisfactory extract ; but, unlike most ferments, owing to its instability the commercial preparation of bromoline has, I believe, so far proved unsuccessful. The reputation of the pineapple has suffered for many reasons ; far too much is eaten at a time and the fibrous part is swallowed as well as the juice. To obtain its full digestive value one quadrant of a moderately (say half an inch) thick slice is ample for one meal; it should be well masticated and the fibrous part rejected. As justly remarked it must not be cooked and it should be just ripe. My experience is that the preserved form has practically no digestive power.

Apart from its being an aid to digestion it has a powerfully solvent action upon plastic exudation-e.g., diphtheria membrane. This is easily demonstrated by exposing a portion of the membrane or some white blood-clot to the action of the juice in a flask, when under favourable conditions of temperature and movement it will soon be dissolved. When, however, applied to the throat, either as a "swab" or spray, in a case of diphtheria, the contact is so short that one cannot expect extensive solu. tion, but it will be found to exert a decidedly softening effect on the sticky and stringy exudation so as to admit of its easy detachment. Again, too, its solvent power is well shown upon thick and horny epidermis in a manner similar to salicylic acid, although somewhat slower in action. If a thin slice of fresh pineapple be kept in close contact with a corn for eight hours it is so softened as to admit of ruady removal. Likewise it softens the horny papillæ in keratosis of the tonsil and rapidly relieves the "pricking sensation." Pineapple juice has evidently wide therapeutic possibilities but for whatever purpose employed it must be borne in mind that the fresh juice alone can be relied upon. I am, Sirs, yours faithlully,

WYATT WINGRAVE, M.D. Durh.

Devonshire-street, W., June 7th, 1902.

\section{CANNABIS INDICA IN CHOREA AND PERTUSSIS.}

To the Editors of THE LANCET.

SrRs,-Farly this year I was called to see a-to merecord case of chorea. The patient, a bright girl, aged 11 years. was suffering from her third attack in five years. I tried increasing doses of Fowler's solution with apparent success, but in a fortnight she was frightened by a steam fire-engine dashing past the house at night and the next morning I found her flinging her arms and legs about with such violence that they were severely bruised against the back and legs of the couch on which she lay. Fearing death from exhaustion I put her on opium, of which it required from three to four grains a day to control the muscles. Then the appetite failed and she had in addition a severe attack of toothache, necessitating the removal of an upper molar under gas, which was only administered with grear difficulty. This operation again intensified the movements and I resorted to Indian hemp, giving her seven and a half minims of the tincture made from Parke, Davis and Co.'s fluid extract every four hours. The effect was magical. Next morning she was lying composed on the couch, looking perfectly happy, with only slight muscular twitching and appetite improving. In three weeks she could dress and feed herself without much assistance and has now been for over two months strong and well. While attending this case $I$ was called to one of pertussis in a boy, aged 22 months. The cough was almost incessant and accompanied with vomiting. I gave him two minims of the tincture of cannabis indica every three hours. The next day I was told he had a very good night, coughing only three times. On the third day the cough had almost ceased and by the end of a week had disappeared. In a second case shortly after, that of a girl, aged five years, I gave five-minim doses every four hours. After the second four-ounce mixture had been finished the mother told me the girl only coughed slightly about once a day. She took no more medicine and is quite well. In all three cases the following points were noticeab e : (1) direct relief to spasm; (2) absence of any head symptoms; and (3) non-interference with appetite or digestion. I may add that only a little chloroform water was added to the tincture to conceal the slightly unpleasant taste and that the mixture was well taken in each ca:e. I am, Sirs, yours faithfully,

Birmingham, June 20th, 1902. E. T. Burton.

\section{INSANITY AND THE DEATH PENALTY. \\ To the Editors of THE LANCET.}

SIRS, - I think that the above subject is one of great importance and I agree with most of the remarks in the leading article in your issue of June 21st, p. 1782 . I wish, however, that you had more strongly condemned the practice adopted at some of these trials-i e., to consider a criminal insane because the court shrinks from the capital sentence. By all means, if the public conscience is averse to capital punishment, let it be abolished, but it is not right that some murderers should suffer the penalty of the law and others get off on the score of insanity who, in the eyes of all except certain "experts," are fully as sane as. the former. At the present time it might be fairly argued that all murderers are insane at the time they commit their crimes. In the majority of criminals of the more brutal type, by examining their past history it is not unlikely that a condition of "minor epilepsy" might be diagnosed. This may be all very well from a psychological point of view, but it is questionable whether it tends to the public safety. I cannot help thinking that the law, as laid down in the McNaughton case, and which is still the law, was far sounder for protecting the public than that inspired by " the tendency towards mercy natural to advancing civilisation." A man makes improper proposals to a barmaid, accompanied by a pecuniary bribe, and on her refusal shoots her. He is exonerated on the ground of "minor epilepsy." A few years ago a girl, aged 19 years, was convicted of murder at the Hertford Assizes and executed. Her crime was the sending poison to an imbecile sister at a public asylum, which the latter unfortunately partook of, and was apparently prompted by an idea that she would obtain by her sister's death a small sum of money in the Savings Bank. Surely. as good a case of insanity might have been made out there. It is more than likely that during the last two years criminals have been executed in this country quite as insane as Simmons.

The object of all punishment is to deter. If it has not this effect it is useless. In the case of an undoubted lunatic it can have no deterrent effect and no good is gained by its infliction. But can it be affirmed with any certainty that punishment would have no deterrent effect on criminals. whose insanity depends on the niceties of expert evidence? Might not the punishment of criminals like simmons tend to make others of his class keep their illicit passions more under control? I cannot help thinking that the safety of the public lies more in that direction than in striving on humanitarian principles to prove every murderer insane in order to escape the penalty of the law.

I am, Sirs, yours faithfully,

M. Greenwood, M.D. Brux., LL. B. Lond.,

Hackney-road, N.E., June 21st, $1902 . \quad$ Barrister-at-Law.

\section{THE LONG FOX MEMORIAL.}

To the Editors of THE LANCET.

SIRs, - At a meeting held in the Chapter House of Bristol Cathedral on May 29th the following resolution was. unanimously adopted :-

That a memorial be established to the late Dr. Ellward Long Fox and that it include: (1) the placing of a tablet in the cathedral; (2) the founding of an annual lecture at University College. Bristol, in some
subject connected with medical science, to be called "The Long Fox. subject connected with medical seience, to be called "The Long Fox Lecture"; (3) the partial supporting of a medical missionary student at.
University College, Bristol, to which the balance of the fund collected University College, Bristol, to which the baland
will be devoted aft er providing for (1) and (2).

We shall be glad to receive any contributions from fritnds: of the late Dr. Fox.

We are, Sirs, yours faithfully, W. W. ASQUITH, 34, College-road, Clifton

E. MARKHAM SKERRIT', $\left.\begin{array}{l}\text { MARKHAM SKERRITT, } \\ \text { Edgecumbe House, Richmond- } \\ \text { hill, Clifton, }\end{array}\right\} \begin{aligned} & \text { Honorary } \\ & \text { secretaries. }\end{aligned}$

June 21st, 1902. 